\title{
Working in partnership to deliver a skills course to social work apprentices: avoiding technological determinism
}

\author{
Chad McDonald \\ Manchester Metropolitan University, UK \\ Rebecca Parry \\ The Open University, UK
}

Keywords: apprentices; collaboration; discussion-led; technology; Covid-19.

\section{The challenge}

In this case study, we discuss how we worked in partnership as learning developers to support first-year students completing a new undergraduate social work apprenticeship. Our focus is on our work with the second cohort of students, who started their programme in January 2021—nearly a year into the Covid-19 pandemic. We had taught on the programme during its inaugural year in 2020, when teaching rapidly moved online due to the pandemic. The initial move online was very much a process of trial and error; some teaching strategies that worked well on campus could not be replicated online. For example, Microsoft Teams—-the video-conferencing software we used-emphasised a single presenter, which hampered the organic development of student-tutor interactions. In addition, we felt the online environment encouraged information giving, which jarred with the discussion-centred approach we had emphasised in our previous teaching.

Reflecting on our experiences in 2020, we challenged ourselves to explore with the second cohort how we could foreground dialogue in an online space to encourage student-led learning. Specific factors influenced our plans. The students had one day a week available for university study, as the rest of their week was devoted to work-based learning. This constrained the amount of time available for us to work with them. All the students were mature learners; some of them had not studied formally since completing their GCSEs in secondary school. They needed to write a 3,000-word reflective essay of 
degree standard within eight weeks of starting their apprenticeship. Our aim was to support the students in developing their knowledge and skills so they could confidently undertake this assignment.

We were asked to work with the students during seven compulsory academic skills sessions. The embedding of skills sessions to help students' transition into university-level study has grown as part of the widening participation agenda in higher education (e.g., Boyle et al., 2019; Cairns et al., 2018; Minogue et al., 2018). However, academic skills sessions have been criticised for dictating vague, non-transferrable 'top tips' to students (Wingate, 2006; 2015), and such approaches can reinforce academic writing as being implicitly white, male and Anglocentric (Dippold, 2019; Sperlinger et al., 2018). Remote teaching could be seen to exacerbate some of these concerns. Richards and Pilcher (2020), for instance, polemically argue that online delivery can further entrench study skills as a key pillar of neo-liberalism in higher education.

Live online sessions and asynchronous resources can present challenges for the discussion-led teaching of academic skills. Microsoft Teams had greatly improved by early 2021. However, it still foregrounded the presenter's screen when sharing slides, which did not feel conducive to discussion-based teaching. At the same time, asynchronous resources can imply that suggested models and strategies are the only solution. This issue can be compounded by a lack of direct interaction between the learning developer and students, meaning that recorded materials can appear as the embodiment of the banking model of education (Freire, 2005). The nature of the apprentices' programme meant we had limited time to work with them directly. Our challenge required us to shape how we used the available technology to ensure that it did not determine our approach or limit opportunities for discussion-led academic skills development.

\section{The response}

Collaboration underpinned our response. As learning developers, we worked with the module co-ordinator to plan how we would support the students. Collectively we identified 
the intended learning outcomes and how we could employ synchronous and asynchronous methods in an interconnected way. While the two learning developers taught three and four sessions respectively, session planning was undertaken collaboratively and enhanced by the module co-ordinator's subject-specific expertise. This approach helped us to consider the implications of our ideas and how we could try to avoid possible pitfalls with online teaching to maximise opportunities for discussion. We jointly reflected on each session, repeatedly challenging each other to articulate how our sessions and related asynchronous activities were helping students to achieve specific learning outcomes.

This approach helped to avoid technological determinism (Kirkwood, 2014); it was vital that our students' needs took centre stage, rather than the technology. We combined the use of asynchronous and synchronous opportunities to encourage student-led learning. Each week we met with the students for 90 minutes in a live session using Microsoft Teams. Our discussions were informed by activities the students had completed prior to the sessions, such as writing short texts or completing research tasks. These activities encouraged the students to reflect on their own study strategies and acted as a springboard for the live sessions, highlighting that the asynchronous materials were part of the learning rather than the learning itself.

Our work emphasised the partnership between the learning developers and students, as both brought suggestions to the sessions. The students were able to develop their own strategies through sharing and responding to ideas and concerns raised by the group. Early in the term, for instance, we considered the sources social workers use in their practice, focusing on legal frameworks, workplace policies and academic texts. In the subsequent asynchronous activity, the students identified sources for their assignment, which they shared in the next live session. This sequential approach provided space for the students to discuss the range and credibility of sources, alongside the challenge of synthesising materials. This example emphasises how our response encouraged the shared exploration of ideas, foregrounding the centrality of dialogue for learning (Alexander, 2020). 


\section{Recommendations}

Our response to the pandemic - an event that has forced us all to keep our distance-was to emphasise the importance of partnerships. Collaborative session development requires time for learning developers and academic colleagues to share and discuss ideas. While there are always a multitude of competing pressures, we feel it is vital that these opportunities for discussion are at the core of learning developers' practice. Working together forced us to clearly articulate what we were setting out to do. We repeatedly asked ourselves: what is the key learning and how can we bring it about?

Our students will always guide the answer to this question. In foregrounding our students' needs, we believe we avoided the trap of technological determinism. We did not present prescriptive expectations or set formulas to our students. Instead, we provided our students with opportunities to share their perspectives to make sense of their learning. In reflecting on the engagement with the sessions, we felt that this was valued by the students. Internal metrics focusing on the students' perceptions of this module-as well as their assignment results-were exceptionally positive. Further research on student perceptions would be informative and may form the basis of a longer paper in due course. In the meantime, the module co-ordinator's feedback emphasised that our support was 'crucial' in giving the students 'scope' and the 'confidence to tackle their first assignment'. In learning from the pandemic, we recommend the reaffirmation of dialogue and collaboration at the heart of learning development.

\section{Acknowledgements}

The authors sincerely thank Rachel Hek and Susie McLagan for supporting our collaborative work on the social work apprenticeship programme. We also thank the apprentices for providing stimulating discussion during our sessions together. 


\section{References}

Alexander, R. (2020) A dialogic teaching companion. London: Routledge.

Boyle, J., Ramsay, S. and Struan, A. (2019) 'The academic writing skills programme: a model for technology-enhanced, blended delivery of an academic writing programme', Journal of University Teaching and Learning Practice, 16(4), pp.1-12. Available at: https://ro.uow.edu.au/jutlp (Accessed: 11 June 2021).

Cairns, J., Hervey, T. and Johnson, O. (2018) 'Neither "bolt-on" nor "built-in": benefits and challenges of developing an integrated skills curriculum through a partnership model', Journal of Learning Development in Higher Education, 0(13), pp.1-22. Available at: https://doi.org/10.47408/ildhe.v0i13.435 (Accessed: 7 October 2021).

Dippold, D. (2019) 'Developing the global graduate: how first year university students narrate their experiences of culture', Language and Intercultural Communication, 19(4), pp.313-327. Available at: https://doi.org/10.1080/14708477.2018.1526939 (Accessed: 7 October 2021).

Freire, P. (2005) Pedagogy of the oppressed. Translated by M. B. Ramos. New York: Continuum.

Kirkwood, A. (2014) 'Teaching and learning with technology in higher education: blended and distance education needs "joined-up thinking" rather than technological determinism', Open Learning, 29(3), pp.206-221. Available at: https://doi.org/10.1080/02680513.2015.1009884 (Accessed: 7 October 2021).

Minogue, L., Murphy, C. and Salmons, K. (2018) ‘Embedding learning development; a model for collaborative practice', Journal of Learning Development in Higher Education, (0)13, pp.1-11. Available at: https://doi.org/10.47408/ildhe.v0i13.443 (Accessed: 7 October 2021). 
Richards, K. and Pilcher, N. (2020) 'Study skills: neoliberalism's perfect Tinkerbell', Teaching in Higher Education. Available at:

https://doi.org/10.1080/13562517.2020.1839745 (Accessed: 7 October 2021).

Sperlinger, T., McLellan, J. and Pettigrew, R. (2018) Who are universities for? Re-making higher education. Bristol: Bristol University Press.

Wingate, U. (2006) 'Doing away with "study skills”', Teaching in Higher Education, 11(4), pp.457-469. Available at: https://doi.org/10.1080/13562510600874268 (Accessed: 7 October 2021).

Wingate, U. (2015) Academic literacy and student diversity: the case for inclusive practice. Bristol: Multilingual Matters.

\section{Author details}

Chad McDonald is a Senior Academic and Study Skills Tutor in the Learner Development team at Manchester Metropolitan University. He previously taught academic skills at the University of Chester, and he has a background in supporting students in their transition to studying in higher education.

Rebecca Parry was recently appointed as an Associate Lecturer in Social Sciences at The Open University. She was previously an Academic Skills Adviser at the University of Chester. Prior to teaching in higher education, Rebecca taught English language and literacy skills in further education, and she has been involved in widening participation in education for over twenty years. 